\title{
Os instrumentos burocráticos da gestão urbana utilizados na implementação da outorga onerosa do direito de construir no município de São Paulo
}

The Bureaucratic Urban Management Tools Used in the Implementation of the Onerous Right to Build in the Municipality of São Paulo

Anderson Kazuo Nakano[a] [D, Rossella Rossetto[b]

[a] Universidade Federal de São Paulo (UNIFESP), Instituto das Cidades, Itaquera, São Paulo, SP, Brasil

[b] Prefeitura do Município de São Paulo, Secretaria Municipal de Desenvolvimento Urbano, São Paulo, SP, Brasil

Como citar: Nakano, A. K., \& Rossetto, R. (2021). Os instrumentos burocráticos da gestão urbana utilizados na implementação da outorga onerosa do direito de construir no município de São Paulo. urbe. Revista Brasileira de Gestão Urbana, v. 13, e20200113. https://doi.org/10.1590/2175-3369.013.e20200113

\section{Resumo}

O atual Plano Diretor Estratégico do Município de São Paulo (PDE-MSP) (Lei Municipal 16.050/2014) reformulou as bases jurídicas da Outorga Onerosa do Direito de Construir (OODC). O presente texto busca compreender como a implementação desse instrumento, visto como parte das "políticas do urbano" discutidas por Eduardo Marques (2018), impacta as operações de instituições governamentais do município paulistano que atuam: (i) nos processos de licenciamento urbanístico das edificações de empreendimentos imobiliários e (ii) no monitoramento dos processos de implementação da OODC. Discute-se também o Conselho Gestor do Fundo Municipal de Desenvolvimento Urbano (FUNDURB). Parte-se da hipótese que a implementação da OODC afeta e modifica as rotinas da administração pública. Para verificar tal hipótese examinam-se os procedimentos e instrumentos segundo metodologia neoinstitucionalista mencionada por Pierre Lascoumes e Patrick Le Galés (2012). Os dados e informações utilizados no trabalho foram obtidos em entrevistas com funcionários públicos, consultas a sites e análise de legislações da Prefeitura do Município de São Paulo (PMSP). As descrições e exames apresentados mostram o envolvimento da OODC em processos e relações rotineiras de gestão urbana cujos instrumentos e práticas burocráticas, operados no interior de estruturas institucionais e de procedimentos administrativos, medeiam as interações entre atores governamentais e não governamentais.

Palavras-chave: Direito urbanístico. Planejamento urbano. Plano diretor. Outorga onerosa do direito de construir. Gestão urbana.

\begin{abstract}
AKN é arquiteto urbanista, doutor em demografia, e-mail: kazuo.nakano@gmail.com

RS é arquiteta urbanista, doutora em arquitetura e urbanismo, e-mail: rossellarossetto@hotmail.com
\end{abstract}


The current Strategic Master Plan of the Municipality of São Paulo (MP-MSP) (Municipal Law 16,050/2014) redefined the legal bases of the Onerous Right to Build (ORB). This text tries to understand how the implementation of this instrument, as part of the "urban policies" discussed by Eduardo Marques (2018), impacts the institutional operations of São Paulo city government. This question expresses the problem which guides the studies about: (i) the insertion of the collection of financial revenues related to the ORB as part of the urban licensing processes of the real estate developments; (ii) the monitoring of these processes and the performance of the financial resources collections obtained from the implementation of the ORB for public accountability and (iii) the Management Board of FUNDURB in whose bank account the funds of those financial resources are deposited. The hypothesis asserts that the implementation of ORB requests the inclusion of routinized proceedings and instruments into the public administration. In order to verify that hypothesis, we address analyses about those proceedings and instruments following the neoinstitutional methodologies mentioned by Pierre Lascoumes and Patrick Le Gale (2012). The data and information used in this work come from the interviews with civil servants, internet sites kept by the São Paulo city government institutions and municipal legislations. The descriptions and examinations presented in the article show the ORB as part of the routinized processes and relationships of urban management whose instruments and bureaucratic practices, operated within institutional structures and administrative procedures, mediate the interactions between governmental and nongovernmental actors.

Keywords: Urban Law. Urban planning. Master plan. Onerous Right to Build. Urban management.

\section{Introdução}

Como instrumento básico da política de desenvolvimento e expansão urbana, é cabível considerar o plano diretor ${ }^{1}$ como parte importante das "políticas do urbano" conforme definição proposta por Eduardo Marques (2018). Para este autor, as "políticas do urbano" consistem no

conjunto de ações do Estado que agem prioritariamente sobre o tecido urbano - o espaço social da cidade e seus territórios -, mesmo que por vezes incidam principalmente sobre os seus moradores. Estão aí incluídas evidentemente as políticas de produção do próprio espaço urbano construído, tanto em sua dimensão de intervenção direta, como as políticas de transportes, infraestrutura urbana e habitação popular, quanto as de regulação estatal das ações privadas de produção do ambiente construído, como as políticas de licenciamento de empreendimentos habitacionais privados (Marques, 2018, p. 14).

Segundo Eduardo Marques (2018), os estudos sobre as "políticas do urbano" abordam necessariamente as "instituições, agências e processos de produção de políticas" juntamente com seus respectivos "atores e padrões de relações e governança". Este texto tem como objetivo apresentar o estudo sobre um elemento específico da "política do urbano" do município de São Paulo relativo à gestão do processo de implementação da Outorga Onerosa do Direito de Construir (OODC) conforme o Plano Diretor Estratégico (PDE) de 2014 (Lei Municipal 16.050). A análise enfoca as "capacidades estatais" (Marques, 2018) utilizadas nos processos técnicos, administrativos, burocráticos e institucionais realizados por funcionários de diferentes setores da Prefeitura do Município de São Paulo (PMSP) na implementação da OODC.

Segundo Eduardo Marques, as "capacidades técnicas e operacionais podem se apoiar em conhecimentos, procedimentos e pessoal gerados por diferentes combinações de agências/burocracias públicas e empresas privadas" (Ibid., p. 19). Assim, buscamos mostrar como ocorre a mobilização de tais capacidades no processo de implementação da OODC realizado rotineiramente por funcionários públicos que trabalham no interior das estruturas institucionais da PMSP e interagem com representantes de

\footnotetext{
1 Segundo o Estatuto da Cidade, Lei Federal 10.257/2001 que regulamenta o capítulo sobre a política urbana da Constituição Federal de 1988 (Artigos 182 e 183), o plano diretor "é o instrumento básico da política de desenvolvimento e expansão urbana" (Artigo 40) por meio do qual se estabelecem as normas que determinam e organizam, no território municipal, as formas e os modos de cumprimento das funções sociais da cidade e das propriedades urbanas.
} 
empresas que atuam na produção imobiliária. Parte-se da hipótese um tanto óbvia de que a implementação da OODC exige a incorporação e acomodação de procedimentos e instrumentos nas rotinas da administração pública.

Para verificar tal hipótese examinamos os dados e informações relativos a procedimentos e instrumentos discutidos segundo referência neoinstitucionalista proposta por Pierre Lascoumes e Patrick Le Galés (2012). Os dados e informações utilizados foram obtidos em entrevistas com funcionários públicos e membro do Conselho Gestor do FUNDURB, consultas a sites e análise de legislações urbanísticas da Prefeitura do Município de São Paulo (PMSP). De acordo com Pierre Lascoumes e Patrick Le Galés, as "instituições são rotinas, procedimentos, convenções, estratégias, formas de organização e tecnologias, mas também crenças, paradigmas, códigos, culturas e conhecimentos que envolvem, sustentam, interpretam ou contradizem rotinas e papéis" (Lascoumes \& Le Galés, 2012, p. 185).

Desse modo, entende-se ainda que a implementação da OODC envolve necessariamente a realização cotidiana de operações institucionais baseadas na utilização de "instrumento de ação pública" que, segundo Pierre Lascoumes e Patrick Le Galés, consiste em "dispositivo simultaneamente técnico e social que organiza relações sociais específicas entre o poder público e seus destinatários em função de representações e de significações de que ele é portador" (Lascoumes \& Le Galés, 2004 apud Lascoumes \& Le Galés, 2012, p. 200). Nesse sentido, os instrumentos jurídicos, administrativos e burocráticos apresentados neste trabalho e utilizados em diferentes momentos de implementação da OODC colocam-se como mediadores e organizadores das relações entre setores distintos da PMSP e os atores sociais envolvidos na produção imobiliária inserida nos espaços urbanos paulistanos.

A utilização dos "instrumentos da ação pública" consiste na "instrumentalização da ação pública [a qual] remete ao conjunto de problemas apresentados pela escolha e o uso de instrumentos (técnicas, formas de operar, dispositivos) que permitem materializar e operacionalizar a ação governamental" (Lascoumes \& Le Galés, 2004 apud Lascoumes \& Le Galés, 2012, p. 200, grifo dos autores). Assim, os instrumentos utilizados na implementação da OODC operacionalizam e materializam a "ação governamental" realizada pela PMSP como parte da implementação do PDE-MSP de 2014 e, por conseguinte, da política e regulação urbana local.

A implementação do PDE-MSP de 2014, ainda em pleno curso, envolve a mobilização de instrumentos e instrumentações da ação pública operados em vários âmbitos institucionais da PMSP. A opção pelo enfoque na implementação da OODC, prevista nos artigos 115, 116, 117, 118, 119 e 120 daquele PDE-MSP de 2014, excluindo os processos relativos à implementação da OODC conforme o PDE-MSP de 2002, justifica-se pela criação da Secretaria Especial de Licenciamento da Prefeitura do Município de São Paulo (SEL-PMSP) em 2013 a qual introduziu mudanças nos processos de licenciamento urbano de novas edificações e de reformas em edificações existentes. Conforme se verá adiante, parte importante da implementação da OODC passou a ocorrer no interior de tais processos rotineiros da gestão urbana local. Processos nos quais se realizam procedimentos técnicos, administrativos, jurídicos, burocráticos e institucionais, dentre outros, voltados para a cobrança da contrapartida financeira relativa à OODC.

Vale dizer que as rotinas internas da administração pública local, envolvidas na gestão da implementação de instrumentos de política urbana como a OODC, não são muito analisadas no campo dos estudos urbanos brasileiros. Em que pese o anúncio sobre um "panorama de implementação nos municípios brasileiros" visto no subtítulo do artigo escrito por Cymbalista et. al (2007) sobre os arcabouços jurídicos urbanísticos de um conjunto de municípios brasileiros, particularmente o Plano Diretor, não há uma análise sobre a implementação da OODC. Os autores optaram por restringir as análises aos conteúdos das legislações urbanísticas municipais.

Em artigo sobre a avaliação das matrizes conceituais da OODC, de autoria de Rezende et. al (2009), também não há análises sobre a implementação desse instrumento de política urbana. Orientações para tal implementação são apresentadas na publicação elaborada por Furtado et. al (2012) para o extinto Ministério das Cidades, há propostas alinhadas com os elementos abordados no presente trabalho. No capítulo sobre a "Implementação da Outorga Onerosa do Direito de Construir - OODC", as autoras enfatizam 
as relações com os processos de "licenciamento urbanístico" de edificações, a necessidade de "Controle social na gestão dos recursos obtidos com a OODC" e a importância do "Monitoramento da dinâmica urbana", particularmente do mercado de terras urbanas.

Na implementação da OODC no município de São Paulo, interagem várias instâncias da administração pública que lidam com as questões urbanas, entre as quais destacam-se as atuais secretarias municipais de Finanças e Desenvolvimento Econômico, de Justiça, de Desenvolvimento Urbano, de Habitação, de Mobilidade e Transportes e do Verde e do Meio Ambiente. Setores da administração municipal indireta, como as empresas de urbanismo (SPUrbanismo), de construção habitacional (COHAB), de transporte público por ônibus (SPTrans) e de execução de obras (SPObras) também atuam com aquelas secretarias de modos mais ou menos articulados. Essa parte estatal do "tecido relacional do Estado", conforme concepção de Eduardo Marques (2003), interage com setores empresariais privados envolvidos nas diferentes instâncias de implementação da OODC, determinada pelas normas estabelecidas pelo PDE-MSP de 2014. Interage, também, com moradores da cidade que se expressam de forma organizada em associações e movimentos sociais, que se fazem presentes em colegiados institucionais de participação com representantes do governo e da sociedade civil.

A implementação da OODC envolve, portanto, vários processos e relações políticas e institucionais que incluem alianças e conflitos de interesses distintos. Para apresentar a análise sobre esses processos, este texto organiza-se em 3 (três) partes que seguem esta Introdução. A primeira parte apresenta algumas características das formulações da OODC no PDE-MSP de 2014. A segunda aborda diferentes aspectos da implementação da OODC conforme aquele PDE-MSP. A terceira traz as considerações finais sobre as principais constatações apresentadas ao longo do texto.

\section{A OODC no plano diretor estratégico do município de São Paulo de 2014}

Dentre os instrumentos incluídos no Plano Diretor Estratégico do Município de São Paulo (PDE-MSP) de 2014, a Outorga Onerosa do Direito de Construir (OODC) é o que contribui mais diretamente para a concretização do objetivo relativo ao "retorno para a coletividade da valorização de imóveis decorrentes dos investimentos públicos" (II, Artigo 6을.

A OODC baseia-se no conceito de solo criado que corresponde às áreas construídas das edificações. É, portanto, um dos instrumentos de política urbana que maneja os potenciais construtivos com finalidades financeiras e de ordenamento do uso e ocupação do solo. Fundamenta-se juridicamente em um entendimento trazido pela aprovação do Estatuto da Cidade (lei federal 10.257/2001) o qual estabelece uma separação entre o direito de propriedade e o direito de construir. De acordo com esse entendimento, o proprietário de um lote urbano tem o seu direito de propriedade garantido constitucionalmente e, para exercer esse direito, deve obedecer aos deveres relativos ao uso e ocupação determinados por legislação urbanística e ambiental.

Em artigo já citado de Vera F. Rezende et al., (2009), há uma revisão bibliográfica a respeito das experiências, matrizes conceituais, definições e controvérsias jurídicas relacionadas com a OODC. Uma das controvérsias jurídicas apresentadas refere-se à "possibilidade de separação entre o direito de construir do direito de propriedade" (Rezende et al., 2009, p. 52). Nessa controvérsia há, de um lado, os trabalhos favoráveis a essa separação cujos argumentos baseiam-se nos "interesses urbanísticos", na "função social [da propriedade]" e no não esvaziamento do "valor econômico [do imóvel]" (Idem, p. 57-58). De outro lado, há os trabalhos desfavoráveis para os quais a limitação da "possibilidade de construir" fere a "essência econômica da propriedade" e representa a subtração de "um direito [o de construir]" e até uma "expropriação" (Rezende et al., 2009, p. 59).

A persistência dessa controvérsia não impede a implementação da OODC no município de São Paulo onde, segundo o PDE-MSP de 2014, o exercício do direito de propriedade exige necessariamente a obediência às normas e parâmetros que regulam o direito de construir no lote, observando as determinações relativas ao uso do seu potencial construtivo estabelecidas pelo poder público municipal. 
Dentre essas determinações incluem-se as exigências de pagamento de contrapartidas financeiras correspondentes à OODC. Em texto sobre os conteúdos desse PDE-MSP de 2014, Nabil Bonduki \& Rossella Rossetto (2018) afirmam que o potencial construtivo adicional acima de um determinado nível básico não pertence a cada proprietário, mas à coletividade como um todo, e por isso é passível de concessão ou outorga onerosa para sua utilização. Segundo os autores,

Essa formulação foi objeto de muitos questionamentos em relação ao direito de propriedade, mas, após a Constituição de 1988 e sobretudo o Estatuto da Cidade, prevaleceu o entendimento de que o direito de construção, estabelecido pelo zoneamento com os Coeficientes de Aproveitamento Máximo (CAM), está separado do direito de propriedade, a ser definido no plano diretor e que corresponde ao Coeficiente de Aproveitamento Básico (CAB). A lógica que fundamenta esse dispositivo é a de que os direitos de construção adicionais ao definido pelo $C A B$ não pertencem a cada proprietário, e sim à coletividade como um todo, e por isso são passíveis de uma concessão, ou outorga, para sua utilização (Bonduki \& Rossetto, 2018, p. 231).

O PDE-MSP de 2002 (Lei Municipal 13.430/2002) instituiu a OODC pela primeira vez no sistema de regulação urbana do município de São Paulo². Similar ao Estoque de Área Edificável associado à Outorga Onerosa do Direito Adicional de Construir, prevista no Projeto de Lei 002 de 1991, proposta interrompida e não instituída de plano diretor, a OODC do PDE-MSP de 2002 operava junto com o Estoque de Potencial Construtivo 3 definido pela Lei de Parcelamento, Uso e Ocupação do Solo de 2004 (Lei Municipal 13.885/2004).

A substituição do PDE-MSP de 2002 pelo de 2014 trouxe nova formulação da OODC, que ampliou bastante o alcance arrecadatório da OODC no município de São Paulo sem, no entanto, mudar as definições das áreas computáveis e não computáveis4. 0 PDE-MSP de 2014 instituiu o Coeficiente de Aproveitamento Básico único igual a 1 (um) em toda a área urbana do município, retomando a ideia incluída na proposta de plano diretor de 1991, e extinguiu toda e qualquer possibilidade de alterá-lo. Os interessados no uso de potenciais construtivos adicionais definidos pelos valores acima desse Coeficiente de Aproveitamento Básico, limitados pelos Coeficientes de Aproveitamento Máximo, devem pagar a contrapartida financeira ao poder público municipal. Tal pagamento deve ser feito durante o processo de licenciamento urbano do empreendimento junto ao órgão responsável e os recursos devem ser depositados no Fundo Municipal de Desenvolvimento Urbano (FUNDURB).

Com a aprovação do novo PDE-MSP, em 2014, iniciou-se um novo capítulo na implementação da OODC no município de São Paulo, com processos de gestão coordenados a partir da organização institucional da prefeitura. 0 presente texto prossegue com descrições e análises sobre a implementação da OODC no que diz respeito:

- Aos procedimentos para o pagamento da contrapartida financeira nos processos de aprovação dos empreendimentos imobiliários;

- À sistematização e publicização dos dados de arrecadação mediante a cobrança de contrapartidas financeiras relativas à OODC;

\footnotetext{
2 A aplicação efetiva da OODC no município de São Paulo iniciou somente em 2004, portanto dois anos após a aprovação do PDEMSP de 2002, com a instituição do Decreto 44.703/2004 que regulamentou as normas de aplicação daquele instrumento de política urbana.

3 Os estoques de potenciais construtivos adicionais consistem na quantidade de área construída que era outorgada onerosamente segundo as regras de aplicação da OODC previstas no PDE-MSP de 2002. Foram instituídos pela Parte II da Lei de Parcelamento, Uso e Ocupação do Solo de 2004 (Lei Municipal 13.885/2004 - Parte II - Planos Diretores Regionais) e quantificados para cada um dos 96 distritos do município de São Paulo conforme o Quadro 8, anexo à Parte III da Lei. Com a aprovação da nova Lei de Parcelamento, Uso e Ocupação do Solo de 2016 (Lei Municipal 16.402/2016), os estoques de potenciais construtivos adicionados deixaram de existir, mas a Divisão de Monitoramento de Uso do Solo de DEUSO/SMDU continua a monitorá-lo.

4 As áreas computáveis e não computáveis correspondem às áreas construídas que são, respectivamente, consideradas e não consideradas nos cálculos dos Coeficientes de Aproveitamento dos lotes utilizados pela edificação. Podem variar conforme os usos residenciais e não residenciais dessas edificações. No município de São Paulo, as áreas não computáveis correspondem, por exemplo, às áreas de terraços, áreas de uso comum localizadas no pavimento térreo, áreas de lazer de uso comum em edificações residenciais, garagens, áreas de circulação de uso comum, áreas técnicas destinadas exclusivamente a instalações e equipamentos, áreas com obras complementares como portarias e passagens cobertas, dentre outras.
} 
- À composição e ao funcionamento do Conselho Gestor do FUNDURB.

\section{Os instrumentos de gestão da implementação da OODC}

Conforme mencionado anteriormente, os artigos 115, 116, 117, 118, 119 e 120 do PDE-MSP de 2014 formularam as bases jurídicas para a aplicação da OODC no município de São Paulo. 0 artigo 115 instituiu a OODC com base no Estatuto da Cidade e determinou que os recursos arrecadados mediante a cobrança de contrapartida financeira fossem destinados ao FUNDURB. 0 artigo 116 definiu o potencial construtivo adicional como "bem jurídico dominical, de titularidade da Prefeitura" a ser dimensionado a partir da aplicação dos Coeficientes de Aproveitamento Básico e Máximo e outorgado onerosamente. 0 artigo 117 estabeleceu a fórmula ${ }^{5}$, procedimentos e parâmetros que devem ser observados no cálculo do valor da contrapartida financeira relativa à OODC. 0 artigo 118 estabeleceu os prazos, procedimentos para publicização, referências e condições para a atualização do Cadastro de Valor de Terreno para fins de Outorga Onerosa. 0 artigo 119 previu o estabelecimento de fator de redução da contrapartida financeira relativa à OODC para "empreendimentos que adotem tecnologias e procedimentos construtivos sustentáveis". Por fim, o artigo 120 estabeleceu o prazo de quatro anos para revisão e atualização dos fatores de planejamento que compõem a fórmula de cálculo do valor da contrapartida financeira relativa à OODC.

Os artigos do PDE-MSP de 2014 mencionados anteriormente permitem que a OODC seja aplicada sem a necessidade de regulamentações posteriores por meio de leis específicas. Para poder empreender e comercializar seus imóveis, os incorporadores imobiliários devem obedecer às normas relativas à OODC já nos processos de licenciamento urbanos, os quais se obtém o Alvará de Aprovação, Alvará de Aprovação e Execução e Certificado de Conclusão de Obras, emitidos pelos técnicos da Prefeitura Municipal do Município de São Paulo (PMSP) alocados na Secretaria Municipal de Licenciamento (SEL), criada em 2013. Esses técnicos realizam as análises e avaliações dos documentos e materiais técnicos relacionados com o empreendimento imobiliário a ser realizado. Uma vez obtida a licença urbanística, o incorporador deve registrar seu empreendimento em cartórios gerais de registros de imóveis.

\section{A OODC no Licenciamento de Novos Empreendimentos Imobiliários}

Os processos de licenciamento urbanístico de novos empreendimentos imobiliários passaram por reestruturações durante o período entre 2013 e 2016 com a criação da Secretaria Municipal de Licenciamento (SEL). Tais reestruturações foram feitas em parceria entre a SEL e Secovi-SP com vistas a introduzir maior agilidade e eficiência nas análises, avaliações e aprovações dos projetos de edificações dos empreendimentos e garantir transparência pública de modo a evitar as conhecidas ocorrências de corrupções ${ }^{6}$.

A SEL coloca-se como um dos setores governamentais estratégicos para a produção imobiliária em interação com os agentes do mercado de incorporação imobiliária. As atividades voltadas para a produção imobiliária envolvem um conjunto grande de atores inseridos em instituições governamentais e não

\footnotetext{
5 Segundo o artigo 117 do PDE-MSP de 2014, a fórmula para o cálculo da contrapartida financeira relativa à OODC é a seguinte: $\mathrm{C}=($ At $/$ Ac) $\times$ V x Fs $\times$ Fp, onde:

$\mathrm{C}$ - contrapartida financeira relativa a cada $\mathrm{m}^{2}$ de potencial construtivo adicional;

At - área de terreno em $\mathrm{m}^{2}$;

Ac - área construída computável total pretendida no empreendimento em $\mathrm{m}^{2}$;

$\mathrm{V}$ - valor do $\mathrm{m}^{2}$ do terreno constante do Cadastro do Valor de Terreno para fins de Outorga Onerosa. Recuperado em 19 de março de 2020, de

https://www.prefeitura.sp.gov.br/cidade/secretarias/upload/C\%C3\%B3pia\%20de\%2020200127_PDE2013_SUBST2_Quadro_1 4_cadastro_atualizado\%20(2).pdf;

Fs - fator de interesse social, entre 0 (zero) e 1 (um);

Fp - fator de planejamento, entre 0 (zero) e 1,3 (um e três décimos).

6 Para mais detalhes a respeito da reestruturação dos processos de licenciamento urbanístico das edificações de empreendimentos imobiliários e da criação da Secretaria Municipal de Licenciamento da Prefeitura do Município de São Paulo, ver artigo elaborado por Telma Hoyler (2018).
} 
governamentais, que incidem nas "políticas do urbano" e compõem o "tecido relacional do Estado", consideradas conforme as definições de Eduardo Marques (2018) apresentadas anteriormente.

Nos processos de licenciamento urbanístico de empreendimentos imobiliários ${ }^{7}$ descrito por Telma Hoyler (2018), a interação entre os técnicos da SEL e os profissionais que atuam no mercado imobiliário ocorre por meio de instrumentos que a autora definiu, inspirada pelas ideias de Pierre Lascoumes e Patrick Le Galés (2012), "como organizadores de relações sociais específicas entre Estado e aqueles a quem os instrumentos são endereçados conforme os significados que carregam" (Hoyler, 2018, p. 187). Hoyler se referiu a esses instrumentos como sendo "artefatos" utilizados em "práticas burocráticas" de instituições públicas (Hoyler, 2018, p. 188).

Os "artefatos" das "práticas burocráticas" constituem-se como documentos utilizados pelos técnicos da SEL no processo administrativo aberto a partir de cada solicitação do Alvará de Aprovação e do Alvará de Aprovação e Execução de um empreendimento imobiliário. Atores públicos e privados que fazem parte do "tecido relacional" que entrelaça setores do governo e da sociedade civil do município de São Paulo, operam os procedimentos cotidianos realizados na mobilização e manuseio dos "artefatos" segundo "práticas burocráticas" rotineiras. Em entrevista ${ }^{8}$ realizada com duas servidoras públicas que trabalham na Secretaria Municipal de Desenvolvimento Urbano (SMDU) da Prefeitura do Município de São Paulo (PMSP), ouve-se que tais procedimentos devem ser muito corretos e documentados porque as "práticas burocráticas" operam segundo normas que regem e limitam as atuações dos servidores públicos. Essas normas são necessárias para evitar que esses servidores atuem contra o interesse público e também para evitar formas de corrupção.

Os "artefatos", constituídos por documentos e instrumentos administrativos, servem para os servidores públicos comprovarem obediência às normas legais e institucionais. Servem também para o compartilhamento de responsabilidades que, desse modo, deixam de recair individualmente sobre os servidores públicos. Ademais, servem ainda para garantir a efetivação do princípio da impessoalidade que rege as interações entre os membros do governo e da sociedade no cotidiano da administração pública municipal.

Nos processos de licenciamento urbanístico de empreendimentos imobiliários, os técnicos da SEL utilizam o "Boletim de Dados Técnicos" (BDT), que consiste em um "documento interno que informa, a partir da sequência numérica Setor-Quadra-Lote, os dados que descrevem a situação natural e legal que incide sobre o lote em questão" (Hoyler, 2018, p. 188). Os técnicos da SEL utilizam também o "Comunique-se", no qual "são listados os documentos ou as plantas que o interessado precisa anexar ao processo ou corrigir no que foi apresentado" (Hoyler, 2018, p. 190).

Curiosamente, Telma Hoyler não menciona a etapa de cobrança e pagamento da contrapartida financeira referente à OODC como parte do licenciamento urbanístico das edificações que fazem parte de empreendimentos imobiliários. A autora, também, não descreve os procedimentos e "artefatos" utilizados na cobrança da contrapartida financeira relativa à $\mathrm{OODC}$, que deve ser vista como parte dos processos de licenciamento urbanístico de edificações e reformas. Tal cobrança faz parte desses processos porque, sem a realização do pagamento de, ao menos, as primeiras parcelas da contrapartida financeira, a SEL não concede o Alvará de Aprovação e sem a quitação do pagamento de todas as parcelas, não concede o Alvará de Aprovação e Execução.

Assim, devemos considerar a cobrança e o pagamento da contrapartida financeira como um ramo dos processos de licenciamento urbanístico das edificações dos empreendimentos imobiliários ${ }^{9}$. A Figura 1 mostra um fluxograma deste ramo, construído com subsídios obtidos a partir de entrevista ${ }^{10}$ realizada com uma servidora da SEL.

\footnotetext{
7 A SEL organiza-se em coordenadorias específicas que analisam e avaliam os empreendimentos imobiliários para sua aprovação e licenciamento urbanístico conforme os tipos de usos da edificação: residenciais, interesse social, comercial/serviços e industrial. 8 A entrevista foi realizada com as profissionais da PMSP no dia 03 de novembro de 2019.

9 A Portaria 18 de 19 de julho de 2015, alterada pela Portaria 19 de julho de 2016, descrevem os procedimentos relativos aos pedidos de Outorga Onerosa do Direito de Construir.

10 A entrevista foi realizada com a profissional da PMSP no dia 02 de dezembro de 2019.
} 




Figura 1 - Fluxograma do Processo de Cobrança da Contrapartida Financeira Relativa à Outorga Onerosa do Direito de Construir. (1) As Subprefeituras alimentam o Sistema de Licenciamento Cadastral Eletrônico com os dados dos processos de licenciamento de edificação com área construída de até $1.500 \mathrm{~m}^{2}$. DEUSO/SMDU e DEINFO/SMDU acessam esse Sistema para a obtenção daqueles dados. (2) Esta planilha encontra-se no seguinte endereço eletrônico: https://www.prefeitura.sp.gov.br/cidade/secretarias/licenciamento/servicos/index.php?p=280585. (3) Com a aprovação da nova Lei de Parcelamento, Uso e Ocupação do Solo de 2016 (Lei Municipal 16.402/2016), os estoques de potenciais construtivos adicionados deixaram de existir, mas a Divisão de Monitoramento de Uso do Solo de DEUSO/SMDU continua a monitorá-lo. (4) No Alvará de Aprovação e no Alvará de Aprovação e Execução deverá constar que a edificação do empreendimento imobiliária foi licenciada com o pagamento de contrapartida financeira relativa à OODC.

Na SEL, os fluxos e responsabilidades na interação com os interessados na obtenção do Alvará de Aprovação e do Alvará de Aprovação e Execução de edificações foram adaptados e modificados ao longo dos 
anos, no sentido de torná-los mais ágeis e com etapas claramente definidas. Uma das modificações se deu nos procedimentos de cálculos dos valores das contrapartidas financeiras relativas à OODC, que passaram a ser feitos pelos interessados. Antes, esse cálculo era feito pelos técnicos da PMSP. Atualmente, o próprio interessado acessa uma planilha ${ }^{11}$ contendo cálculos pré-determinados dos valores devidos. Esses cálculos devem ser feitos a cada solicitação do Alvará de Aprovação e do Alvará de Aprovação e Execução. 0 interessado deve apresentar um formulário com o valor da contrapartida financeira calculada especificamente para o seu empreendimento imobiliário.

No fluxograma da Figura 1, vale atentar para o documento emitido pela SEL para que os interessados possam efetuar os pagamentos integrais ou parcelados das contrapartidas financeiras relativas à OODC. Esse documento consiste em uma guia de recolhimento, a partir da qual os solicitantes fazem tais pagamentos das contrapartidas financeiras em instituições financeiras. 0 valor pago é depositado diretamente em conta bancária do FUNDURB. Com isso, o processo ocorre com um caráter impessoal condizente com um dos princípios básicos da administração pública e da governança urbana.

Ainda no fluxograma da Figura 1, destaca-se o momento final em que a SEL emite o Alvará de Aprovação e o Alvará de Aprovação e Execução de edificações para o interessado. Com isso, finda a etapa de arrecadação da contrapartida financeira relativa à OODC que, entre janeiro de 2004 e janeiro de 2018, tinha acumulado um montante de $\mathrm{R} \$ 335.075 .235,42^{12}$. A sistematização deste dado, obtido no acervo de monitoramento da implementação do PDE-MSP de 2014 pelo Departamento de Produção e Análise de Informação (DEINFO) da Secretaria Municipal de Desenvolvimento Urbano (SMDU), resulta de um trabalho realizado em outra etapa de implementação da OODC, que consiste na alimentação de uma planilha organizada pelo Departamento de Uso e Ocupação do Solo (DEUSO) que também faz parte da SMDU. Os dados sistematizados nessas duas linhas de monitoramento da OODC são de acesso público na internet.

\section{A Sistematização dos Dados Relativos à Implementação da Outorga Onerosa do Direito de Construir e os Recursos Arrecadados no Período Recente}

A última etapa do processo de cobrança e pagamento da contrapartida financeira relativa à OODC consiste na sistematização dos dados pelo Departamento de Produção e Análise de Informação (DEINFO) e de Uso e Ocupação do Solo (DEUSO) da Secretaria Municipal de Desenvolvimento Urbano (SMDU). Esses Departamentos realizam, dentre outras atribuições, o monitoramento da implementação da OODC. O DEINFO sistematiza dados agregados com o objetivo de demonstrar os desempenhos dos recursos arrecadados com as contrapartidas financeiras relativas à OODC, seus usos no financiamento das intervenções nos espaços urbanos da cidade. O DEUSO sistematiza dados relativos a cada processo de licenciamento urbanístico das edificações dos empreendimentos imobiliários obrigados a pagar contrapartidas financeiras relativas à OODC.

O DEINFO sistematiza os dados ${ }^{13}$ da receita do FUNDURB, sua distribuição segundo políticas setoriais (habitação social; mobilidade; equipamentos urbanos e sociais; áreas protegidas, verdes e espaços livres; saneamento ambiental; proteção ao patrimônio cultural; planejamento local e projeto de intervenção urbana), sua distribuição territorial e da distribuição de potencial construtivo adicional utilizado por

\footnotetext{
11 Essa planilha pode ser acessada no link

https://www.prefeitura.sp.gov.br/cidade/secretarias/licenciamento/servicos/index.php?p=280585. Acesso em 19/03/2020.

12 Dado sistematizado pelo DEINFO obtido no site "Gestão Urbana SP" mantido pela Secretaria Municipal de Desenvolvimento Urbano (SMDU) da Prefeitura do Município de São Paulo (PMSP) https://monitoramentopde.gestaourbana.prefeitura.sp.gov.br/. Acesso em 19/03/2020. Como o valor de $\mathrm{R} \$ 335.075 .235,42$ corresponde ao montante acumulado de recursos arrecadados via aplicação da OODC no período entre janeiro de 2004 e janeiro de 2018, entende-se que nesse montante somam-se a arrecadação baseada no PDE-MSP de 2002 e no PDE-MSP de 2014.

13 Esses dados podem ser obtidos no site "Gestão Urbana SP" mantido pela Secretaria Municipal de Desenvolvimento Urbano (SMDU) da Prefeitura do Município de São Paulo (PMSP). Recuperado em 19 de março de 2020, de https://monitoramentopde.gestaourbana.prefeitura.sp.gov.br/.
} 
Coeficiente de Aproveitamento utilizado e por territórios. A Tabela 1 mostra os valores das arrecadações acumuladas e sua participação na receita anual ${ }^{14}$ acumulada do FUNDURB.

O DEUSO sistematiza dados ${ }^{15}$ dos processos referentes à OODC e do estoque de potencial construtivo adicional revogado. Os dados são atualizados permanentemente em planilha de acesso público com número e situação institucional do processo acompanhado pelas informações a respeito do empreendimento imobiliário: número do setor-quadra-lote, endereço completo, codlog, distrito, área do terreno ( $\mathrm{em}^{2}$ ); coeficientes de aproveitamento básicos (projeto e utilizado), categoria e tipo de uso, área excedente (em $\mathrm{m}^{2}$ ), valor da contrapartida financeira (em R\$) e número do Alvará de Aprovação e do Alvará de Aprovação e Execução.

Tabela 1 - Participação dos Montantes de Recursos Acumulados via Arrecadação da OODC na Receita Anual Acumulada do FUNDURB no Período Entre 01/012012 e 01/01/2018

\begin{tabular}{llll}
\hline Ano & $\begin{array}{l}\text { Receita Anual Acumulada do } \\
\text { FUNDURB (R\$) }\end{array}$ & $\begin{array}{l}\text { Montante Acumulado Anualmente via } \\
\text { Arrecadação da OODC (R\$) }\end{array}$ & $\%$ \\
\hline $01 / 01 / 2012$ & $212.056 .890,09$ & $193.047 .680,55$ & 91,0 \\
$01 / 01 / 2013$ & $311.436 .555,64$ & $300.833 .739,93$ & 96,6 \\
$01 / 01 / 2014$ & $227.562 .823,1$ & $206.776 .881,5$ & 90,9 \\
$01 / 01 / 2015$ & $265.504 .393,48$ & $249.973 .455,46$ & 94,2 \\
$01 / 01 / 2016$ & $231.396 .111,72$ & $209.947 .937,53$ & 90,7 \\
$01 / 01 / 2017$ & $231.952 .509,95$ & $210.187 .562,35$ & 90,6 \\
$01 / 01 / 2018$ & $400.602 .944,84$ & $335.075 .235,42$ & 83,6 \\
$01 / 01 / 2012$ & $212.056 .890,09$ & $193.047 .680,55$ & 91,0 \\
$01 / 01 / 2013$ & $311.436 .555,64$ & $300.833 .739,93$ & 96,6 \\
$01 / 01 / 2014$ & $227.562 .823,1$ & $206.776 .881,5$ & 90,9 \\
\hline
\end{tabular}

Fonte: SMDU-PMSP - Site Gestão Urbana SP - Monitoramento PDE -

https://monitoramentopde.gestaourbana.prefeitura.sp.gov.br/ - acesso em 19/03/2020.

Na Tabela 1 nota-se a relevância da arrecadação acumulada de contrapartidas financeiras relativas à OODC no total da receita acumulada anualmente do FUNDURB, nos anos entre 2012 e 2018. Com exceção deste último ano, quando a receita acumulada do FUNDURB foi de 400,6 milhões de reais, nos demais anos a arrecadação acumulada via aplicação da OODC correspondeu a mais de $90 \%$ dessa receita acumulada que variou de um mínimo de 212 milhões em 2012 a um máximo de 311,4 milhões em 2013. É importante observar que após a aprovação do PDE-MSP, ocorrida no segundo semestre de 2014, a OODC passou a ser aplicada segundo normas diferentes das que estavam em vigência anteriormente.

É interessante notar que, logo após a aprovação do PDE-MSP em 2014, a economia brasileira e o mercado imobiliário paulistano entraram em um período de recessão no qual, mesmo com a redução na quantidade de empreendimentos imobiliários lançados, não houve reduções significativas no montante arrecadado mediante a cobrança de contrapartidas financeiras relativas à OODC. Vale observar, também, que a ligeira recuperação econômica verificada em 2018 provocou a elevação na quantidade de lançamentos imobiliários no município de São Paulo e, com isso, o aumento significativo na arrecadação de recursos via OODC cujo montante acumulado alcançou o patamar de R \$335.075.235,42 o qual, conforme a Tabela 1 , coloca-se no nível mais alto desde 2012.

Com relação à utilização dos recursos arrecadados com a aplicação da OODC, é preciso observar os Artigos 339 e 340 do PDE-MSP de 2014 que estabelecem as normas para a sua destinação. Segundo o primeiro Artigo, tais recursos devem financiar ações relativas à habitação de interesse social; mobilidade

\footnotetext{
14 As receitas anuais do FUNDURB no período entre 2012 e 2018 foram compostas por recursos oriundos da Outorga Onerosa do Direito de Construir; de acordos, contratos, consórcios e convênios; da Cota de Solidariedade; das multas e juros recebidos em decorrência de suas aplicações; de outras receitas eventuais; de rendimentos obtidos com a aplicação do seu próprio patrimônio. 15 Esses dados podem ser obtidos em planilha que pode ser acessada no link

https://www.prefeitura.sp.gov.br/cidade/secretarias/urbanismo/legislacao/estoques_de_potencial_construtivo/index.php?p=1384.
} 
ativa e por meio de transporte coletivo público; saneamento básico; parques lineares; equipamentos urbanos e comunitários; espaços públicos de lazer; áreas verdes; bens e áreas de valor histórico, cultural e paisagístico e unidades de conservação e de outras áreas de interesse ambiental. De acordo com o segundo Artigo, deve-se priorizar a obtenção de terrenos bem localizados ${ }^{16}$ para habitação de interesse social (30\% daqueles recursos) e os investimentos na melhoria da mobilidade ativa (cicloviária e de pedestres) e dos transportes públicos coletivos (outros 30\% daqueles recursos).

Retornando aos dados de monitoramento do PDE-MSP de 2014, feito pelo DEUSO, nota-se a existência de fluxo na utilização dos recursos do FUNDURB no período entre 01/01/2013 e 01/01/2018. A Tabela 2 mostra, nesse fluxo, as despesas realizadas com aqueles recursos.

Tabela 2 - Fluxo de Despesas Realizadas com Recursos do FUNDURB no Período Entre 01/01/2013 e 01/01/2018

\begin{tabular}{lcccc}
\hline Anos & $\begin{array}{l}\text { Montante Acumulado de } \\
\text { Recursos do FUNDURB (RS) }\end{array}$ & $\begin{array}{l}\text { Despesas Anuais } \\
\text { Realizadas com Recursos } \\
\text { do FUNDURB (R\$) }\end{array}$ & Saldo & $\begin{array}{l}\text { \% Montante } \\
\text { Acumulado de } \\
\text { Recursos do } \\
\text { FUNDURB }\end{array}$ \\
\hline $01 / 01 / 2013$ & $523.493 .445,73$ & $231.925 .637,79$ & $291.567 .807,94$ & 55,7 \\
$01 / 01 / 2014$ & $519.130 .631,04$ & $335.297 .085,35$ & $183.833 .545,69$ & 35,4 \\
$01 / 01 / 2015$ & $449.337 .939,17$ & $262.300 .819,02$ & $187.037 .120,15$ & 41,6 \\
$01 / 01 / 2016$ & $418.433 .231,87$ & $236.445 .178,43$ & $181.988 .053,44$ & 43,5 \\
$01 / 01 / 2017$ & $413.940 .563,39$ & $106.868 .739,83$ & $307.071 .823,56$ & 74,2 \\
$01 / 01 / 2018$ & $707.674 .768,40$ & $131.865 .938,44$ & $575.808 .829,96$ & 81,4 \\
\hline
\end{tabular}

Fonte: SMDU-PMSP - Site Gestão Urbana SP - Monitoramento PDE. Recuperado em 19 de março de 2020 de https://monitoramentopde.gestaourbana.prefeitura.sp.gov.br/.

Na Tabela 2, percebe-se a diminuição das despesas no total de recursos do FUNDURB e, consequentemente, o crescimento do saldo positivo tanto em números absolutos quanto relativos. Isso demonstra baixa utilização dos recursos do FUNDURB em investimentos no espaço urbano. Este fato contrasta com as demandas por esses investimentos em inúmeros locais, com péssimas condições de vida urbana existentes na cidade de São Paulo.

\section{Conselho Gestor dos Recursos do Fundo Municipal de Desenvolvimento Urbano}

De acordo com o Artigo 52, inciso IV, do Estatuto da Cidade, o prefeito do município incorre em improbidade administrativa caso aplique os recursos arrecadados com a OODC em desacordo com as determinações legais. Segundo Camila Maleronka e Fernanda Furtado (2013), essa norma torna praticamente obrigatória a criação de fundos especiais para gerir os recursos auferidos com a aplicação da OODC (Maleronka \& Furtado, 2013, p. 7). E, conforme a Lei 4.320/1964, a criação desses fundos requer a criação de um conselho gestor.

Assim, a instituição da OODC pelo PDE-MSP de 2002 foi acompanhada pela criação do já mencionado FUNDURB e do seu respectivo Conselho Gestor. Após a aprovação do PDE-MSP de 2002, a PMSP instituiu uma série de 6 (seis) decretos municipais ${ }^{17}$ regulamentando diferentes composições do Conselho Gestor. 0 Quadro 1 mostra as composições definidas por cada um desses decretos.

\footnotetext{
16 Nas Macroáreas de Estruturação Metropolitana, de Urbanização Consolidada e de Qualificação da Urbanização demarcadas predominantemente nas porções centrais e intermediárias da área urbanizada do município de São Paulo.

17 Trata-se dos decretos 43.231/2003, 43.811/2003, 47.661/2006 e 51.437/2010.
} 
Os instrumentos burocráticos da gestão urbana utilizados na implementação da outorga onerosa do direito de construir no município de São Paulo

Quadro 1 - Alterações nas composições do Conselho Gestor do FUNDURB no período entre 2003 e 2018

\begin{tabular}{|c|c|c|c|c|c|c|}
\hline \multirow{2}{*}{$\begin{array}{l}\text { Segmentos representados } \\
\text { no Conselho Gestor do } \\
\text { FUNDURB }\end{array}$} & \multicolumn{6}{|c|}{ Número de Representantes } \\
\hline & $\begin{array}{l}\text { Decreto } \\
\text { Municipal } \\
43.231 / 2003\end{array}$ & $\begin{array}{l}\text { Decreto } \\
\text { Municipal } \\
43.811 / 2003\end{array}$ & $\begin{array}{l}\text { Decreto } \\
\text { Municipal } \\
47.661 / 2006 \\
\end{array}$ & $\begin{array}{l}\text { Decreto } \\
\text { Municipal } \\
51.437 / 2010\end{array}$ & $\begin{array}{l}\text { Decreto } \\
\text { Municipal } \\
57.547 / 2016 \\
\end{array}$ & $\begin{array}{l}\text { Decreto } \\
\text { Municipal } \\
58.440 / 2018\end{array}$ \\
\hline Secretarias Municipais & $6(1)$ & $7(5)$ & $8(6)$ & $10(7)$ & $5(8)$ & $5(10)$ \\
\hline Subprefeituras & $8(2)$ & $8(2)$ & 0 & 0 & 0 & 0 \\
\hline $\begin{array}{l}\text { Empresa Municipal de } \\
\text { Urbanização (EMURB) } \\
\text { posteriormente } \\
\text { SPUrbanismo }\end{array}$ & 1 & 1 & 0 & 0 & 0 & 0 \\
\hline $\begin{array}{l}\text { Companhia } \\
\text { Metropolitana de } \\
\text { Habitação de São Paulo } \\
\text { (COHAB) }\end{array}$ & 1 & 1 & 0 & 0 & 0 & 0 \\
\hline $\begin{array}{l}\text { Conselho Municipal de } \\
\text { Política Urbana (CMPU) }\end{array}$ & $1(3)$ & $1(3)$ & $2(3)$ & $3(3)$ & $2(9)$ & $2(9)$ \\
\hline $\begin{array}{l}\text { Conselho Municipal de } \\
\text { Habitação (CMH) }\end{array}$ & 0 & 0 & 0 & 0 & $1(9)$ & $1(9)$ \\
\hline $\begin{array}{l}\text { Conselho Municipal de } \\
\text { Trânsito e Transporte }\end{array}$ & 0 & 0 & 0 & 0 & $1(9)$ & $1(9)$ \\
\hline $\begin{array}{l}\text { Conselho Municipal do } \\
\text { Meio Ambiente e } \\
\text { Desenvolvimento } \\
\text { Sustentável }\end{array}$ & 0 & 0 & 0 & 0 & $1(9)$ & $1(9)$ \\
\hline $\begin{array}{l}\text { Entidades da Sociedade } \\
\text { Civil }\end{array}$ & $8(4)$ & $8(4)$ & 0 & 0 & 0 & 0 \\
\hline Total & 25 & 26 & 10 & 13 & 10 & 10 \\
\hline
\end{tabular}

Notas: (1) Um representante por secretaria (Secretarias de Finanças e Desenvolvimento Econômico, do Verde e do Meio Ambiente, da Habitação e Desenvolvimento Urbano, de Infra-Estrutura Urbana, do Governo Municipal, das Subprefeituras). (2) Um representante das Subprefeituras das Macrorregiões Norte 1, Norte 2, Oeste, Centro, Leste 1, Leste 2, Sul 1 e Sul 2. (3) Não determina que o representante do Conselho Municipal de Política Urbana deve ser definido dentre os representantes dos segmentos da sociedade civil. (3) Um representante de entidades da sociedade das Macrorregiões Norte 1, Norte 2, Oeste, Centro, Leste 1, Leste 2, Sul 1 e Sul 2. (4) Inclui um representante da Secretaria Municipal de Transportes dentre os representantes de secretarias definidos pelo Decreto Municipal 43.231/2003. (5) As secretarias passaram a ser representadas pelos titulares das pastas e no caso de impossibilidade de comparecimento destes às reuniões, pode-se designar os respectivos suplentes cuja indicação deve recair sobre o Secretário-Adjunto ou Chefe de Gabinete da Pasta. As secretarias representadas são as de Planejamento, de Finanças, do Verde e do Meio Ambiente, de Habitação, de Infra-Estrutura Urbana e Obras, do Governo Municipal, de Coordenação das Subprefeituras e de Transportes. (6) Idem ao item (5). As secretarias representadas são as de Desenvolvimento Urbano, de Finanças, do Verde e do Meio Ambiente, de Habitação, de Infra-Estrutura Urbana e Obras, do Governo Municipal, de Coordenação das Subprefeituras, de Transportes e de Cultura. (7) Idem ao item (6). As secretarias representadas são as de Desenvolvimento Urbano, do Governo Municipal, de Finanças e Desenvolvimento Econômico, de InfraEstrutura Urbana e Obras e de Habitação. (8) Determina expressamente que os representantes dos colegiados devem ser da sociedade civil e observar as normas de paridade de gênero. (9) Idem ao item (6). As Secretarias do Governo Municipal, de InfraEstrutura Urbana e Obras e de Habitação foram substituídas, respectivamente, pelas Secretarias de Justiça e de Gestão e por um representante do Gabinete do Prefeito. Fonte: Os autores.

É interessante observar que as mudanças na composição do Conselho Gestor do FUNDURB realizadas por meio de Decretos Municipais ocorreram de modo a restringir gradativamente a participação dos representantes de segmentos da sociedade civil e aumentar o predomínio da participação governamental. Tais mudanças se tornaram possíveis porque a Lei Municipal que instituiu o PDE-MSP de 2002 (Lei Municipal 13.430/2002) não definiu a composição do Conselho Gestor no ato da sua instituição. Com isso, aprende-se que as leis que instituem quaisquer Conselhos Gestores devem definir suas composições básicas para garantir representatividade de diferentes segmentos da sociedade civil, principalmente os mais vulneráveis que envolvem as populações com menor poder aquisitivo. 0 mesmo vale para as atribuições e 
funcionamentos desses Conselhos Gestores que devem atuar com certa estabilidade nos processos de implementação de políticas públicas.

Somente com a aprovação da Lei Municipal do PDE-MSP de 2014 (Lei Municipal 16.050/2014), a composição do Conselho Gestor do FUNDURB tornou-se paritária com 5 (cinco) representantes do governo municipal e 5 (cinco) representantes da sociedade civil oriundos dos Conselhos Municipais de Política Urbana, de Habitação, de Trânsito e Transporte e de Meio Ambiente e Desenvolvimento Sustentável. Os Decretos Municipais instituídos posteriormente ao PDE-MSP de 2014, os quais regulamentaram o FUNDURB e seu respectivo Conselho Gestor, não puderam modificar aquela paridade instituída por meio de Lei Municipal. Tais Decretos substituíram algumas secretarias municipais com assentos no Conselho Gestor sem alterar a composição dos representantes da sociedade civil e, portanto, sem modificar a paridade entre as quantidades de membros governamentais e não governamentais.

Porém, a paridade entre as representações do governo municipal e da sociedade civil, na composição do Conselho Gestor do FUNDURB, não significa maior democratização nos processos de tomadas de decisão em relação aos usos e destinações dos recursos financeiros. Os representantes da sociedade civil presentes naquele Conselho Gestor não incidem profundamente na elaboração anual dos planos de aplicação daqueles recursos que são elaborados pelas equipes de diferentes secretarias municipais nos começos de cada ano, com base na previsão de arrecadação das contrapartidas financeiras relativas à OODC para o ano. Em seguida, os planos são apresentados na primeira das quatro reuniões do Conselho Gestor do FUNDURB realizadas ao longo do ano.

É importante ressaltar o fato de que a existência do Conselho Gestor do FUNDURB, bem como de outros canais institucionais de participação social e popular nas políticas públicas, faz com que a gestão urbana se abra às atuações e opiniões de diferentes atores sociais, governamentais e não governamentais, ao abrir canais de pressão e de interlocução social e institucional, muitas vezes conflitantes, nos processos e nas práticas burocráticas. A participação de representantes da sociedade civil no Conselho Gestor do FUNDURB pode não mudar e tampouco definir os resultados das decisões tomadas pelas equipes de funcionários e dirigentes das secretarias municipais, mas certamente afeta o modo como as decisões são tomadas na medida em que precisam ser apresentadas, discutidas e defendidas perante os membros do Conselho Gestor.

\section{Considerações finais}

Ao se debruçar sobre instrumentos de gestão urbana utilizados nos processos internos de órgãos governamentais envolvidos com a implementação da OODC no município de São Paulo, percebe-se que as interações entre setores governamentais e da sociedade ocorrem segundo procedimentos padronizados e em torno de protocolos estabelecidos por normas e documentos que, uma vez criados e instituídos, passam a fazer parte de práticas rotineiras de servidores públicos do governo local. Ao estudar a gestão da implementação da OODC na administração pública, nota-se, de um lado, a utilização de procedimentos, práticas e instrumentos administrativos e burocráticos já existentes, como os que são mobilizados no licenciamento urbano de empreendimentos imobiliários. De outro lado, nota-se a criação de novos procedimentos, práticas e instrumentos, como a planilha de cálculo do valor da contrapartida financeira relativa à OODC pelo interessado e o Termo de Compromisso de Pagamento Parcelado da Outorga Onerosa de Potencial Construtivo Adicional, emitido e assinado durante o processo de licenciamento urbano de novos empreendimentos imobiliários.

A articulação entre rotinas da gestão urbana é algo corriqueiro e necessário na gestão urbana. Na implementação da OODC no município de São Paulo há a articulação entre, de um lado, as rotinas de análise e avaliação de projetos edilícios e, de outro lado, as rotinas para os cálculos e as cobranças das contrapartidas financeiras relativas à OODC. Essas duas rotinas articulam-se com duas rotinas distintas de monitoramento que organizam planilhas de dados sobre: (i)os processos de licenciamento urbano de empreendimentos imobiliários que envolvem pagamentos de contrapartidas financeiras relativas à OODC (monitorados pelo DEUSO da SMDU-PMSP); (ii) os recursos financeiros arrecadados e utilizados com as cobranças das contrapartidas financeiras relativas à OODC, bem como dos potenciais construtivos 
adicionais outorgados onerosamente (monitorados pelo DEINFO da SMDU-PMSP) ${ }^{18}$. Essas planilhas são constantemente atualizadas e dispostas para consulta e uso públicos. Isso contribui para fortalecer a transparência e a prestação de contas públicas e auxilia a evitar corrupções.

Outra percepção importante a respeito dos procedimentos, práticas e instrumentos de gestão urbana, operados internamente por órgãos do governo local para a implementação da OODC, diz respeito à participação social no Conselho Gestor do FUNDURB em cuja conta bancária são depositados os recursos das contrapartidas financeiras relativas à OODC. Percebe-se que a existência do Conselho Gestor do FUNDURB é importante, pois afeta positivamente os processos governamentais de tomadas de decisão. Porém, esses processos necessitam de aperfeiçoamento para que sua democratização seja efetiva. 0 fortalecimento da participação de representantes de movimentos populares e dos grupos mais vulneráveis exige mais do que a paridade entre representantes do governo e da sociedade na composição do Conselho Gestor.

Os representantes da sociedade civil que participam do Conselho Gestor do FUNDURB somente aprovam os planos de aplicação dos recursos financeiros. Podem apresentar propostas a serem incluídas nos planos, porém, segundo entrevista ${ }^{19}$ realizada com uma liderança do movimento popular de luta por moradia, que participou do Conselho Gestor do FUNDURB por dois mandatos no período entre 2015 e 2019, os representantes da sociedade civil sempre perdem no momento da votação porque nunca estão presentes em número suficiente. Isso mostra as dificuldades e desarticulações enfrentadas por esses representantes em suas atuações no Conselho Gestor.

De acordo com a liderança entrevistada, falta apoio operacional para que os representantes atuem com mais qualidade nas discussões, debates e processos de trabalho. As informações fornecidas aos representantes da sociedade civil são importantes, mas precisam ser inseridas em sistemas que permitam maior clareza e agilidade nos acompanhamentos, monitoramentos e avaliações dos investimentos executados. Tais sistemas podem servir para a realização de devolutivas à sociedade de uma maneira geral, com uma visão ampla em relação aos desempenhos daqueles investimentos. Caso ocorressem, as devolutivas poderiam contribuir diretamente para fortalecer e efetivar os canais de participação social e popular nas políticas públicas. Esses canais se mostram imprescindíveis em contextos antidemocráticos, com governantes avessos à interação e interlocução com todos os setores da sociedade.

\section{Referências}

Bonduki, N., \& Rossetto, R. (2018). A reforma urbana no Plano Diretor Estratégico de São Paulo de 2002 e 2014 . In N. Bonduki (org.), A Luta pela reforma urbana no Brasil: Do Seminário de habitação e reforma urbana ao Plano Diretor de São Paulo. São Paulo: Instituto Casa da Cidade.

Brasil. (2001). Câmara dos Deputados. Estatuto da Cidade. Guia para a implementação pelos Municípios. Brasília: Câmara dos Deputados.

Cymbalista, R., Pollini, P., Cobra, P., \& Santoro, P. (2007). “A outorga onerosa do direito de construir após o Estatuto da Cidade - um panorama de implementação nos municípios brasileiros”. R. B. Estudos Urbanos e Regionais (9), 73-93.

Furtado, F., Biasotto, R., \& Maleronka, C. (2012). Outorga onerosa do direito de construir: caderno técnico de regulamentação e implementação. Brasília: Ministério das Cidades.

Hoyler, T. (2018). “O cotidiano esquecido da regulação na produção habitacional privada”. In E. Marques (org.). As políticas do urbano em São Paulo (pp. 173-199). São Paulo: Editora UNESP; Centro de Estudos da Metrópole.

Lascoumes, P., \& Le Galés, P. (2012). Sociologia da ação pública. Maceió: EDUFAL.

18 Conforme visto anteriormente, o monitoramento da implementação da OODC feito pelo DEINFO da SMDU-PMSP faz parte de um sistema de monitoramento de todos os componentes do PDE-MSP de 2014.

${ }_{19}$ A entrevista com a liderança de movimento popular de luta por moradia que participou do Conselho Gestor do FUNDURB foi realizada no dia 12 de dezembro de 2019. 
Maleronka, C., \& Furtado, F. (2013). A Outorga Onerosa do Direito de Construir (OODC): A Experiência de São Paulo na Gestão Pública de Aproveitamentos Urbanísticos. Documento de Trabalho Lincoln Institute of Land Policy. Recuperado em 05 de abril de 2020, de https://www.lincolninst.edu/sites/default/files/pubfiles/maleronka-wp14cm1po-full_0.pdf

Marques, E. (2018). Como estudar as políticas do urbano?. In E. Marques (org.). As políticas do urbano em São Paulo (pp. 1343). São Paulo: Editora UNESP; Centro de Estudos da Metrópole.

Marques, E. (2003). Redes sociais, instituições e atores políticos no governo da cidade de São Paulo. São Paulo: Annablume.

Rezende, V. F., Furtado, F., Oliveira, M. T. C., \& Jorgensen Jr., P. (2009). A outorga onerosa do direito de construir - uma necessária avaliação das matrizes conceituais. R. B. Estudos Urbanos e Regionais, 11(2), 51-71.

Editor responsável: Rodrigo Firmino

Recebido: 05 abr. 2020

Aprovado: 03 set. 2020 